\title{
(C. COBENGE \\ UMA ABORDAGEM LÚDICA PARA O ENSINO DE PROGRAMAÇÃO PARA ADOLESCENTES NO CONTEXTO DA PANDEMIA DE COVID-19
}

\author{
DOI: 10.37702/2175-957X.COBENGE.2021.3558
}

Deise Monquelate Arndt - deise.arndt@ifsc.edu.br Intituto Federal de Santa Catarina Rua Lino Kretzer 608 88103-310 - São José - SC

Evanaska Maria Barbosa Nogueira - evanaska.nogueira@ifsc.edu.br Instituto Federal de Santa Catarina Rua José Lino Kretzer 608 88103-310 - São José - SC

Carlyle Câmara Santos Júnior - carlyle.camara@ifsc.edu.br Instituto Federal de Santa Catarina

Rua Apeninos 100

88037-620 - Florianópolis - SC

Diego da Silva de Medeiros - diegomedeiros@ifsc.edu.br Instituto Federal de Santa Catarina

Rua Lino Kretzer 608

88103-310 - São José - SC

André Luiz Faraco Mazucheli - alfmazucheli@gmail.com Instituto Federal de Santa Catarina

R. José Agenor da Luz 20 88113-317 - São José - SC

Jean Mota Caitano Dos Reis - jeanmcaitano@gmail.com Instituto Federal de Santa Catarina

Rua Nova Veneza 723

88133-050 - PALHOCA - SC

Resumo: A área de tecnologias de informação e comunicação (TIC) tem 
contribuído significativamente para o desenvolvimento econômico de muitas cidades brasileiras nos últimos anos, o que representa uma grande oportunidade de inserção profissional para o público jovem. Este artigo relata os resultados de um projeto de extensão que ocorre desde 2018, que propõe apresentar a área tecnológica como mercado de trabalho viável para estudantes do 9o ano de escolas públicas através de oficinas de linguagens de programação de computadores. Nas primeiras edições do projeto, os estudantes adolescentes eram introduzidos ao mundo da tecnologia por meio do ensino de programação, o que se baseava em abordagens lúdicas que faziam uso de ferramentas didáticas tais como Scratch, Lightbot e micro:bit. Em 2020, por conta das regras de distanciamento social impostas pela pandemia do novo coronavírus, o projeto teve seu escopo modificado. A equipe de trabalho adaptou o material de apoio e produziu videoaulas de ensino de programação através da criação de aplicativos para celular utilizando a ferramenta educacional App Inventor, que foi escolhida por propósitos motivacionais. Os vídeos foram disponibilizados em um canal no YouTube. Ao todo, oito vídeos foram gravados por alunos bolsistas do projeto, os quais abrangem conteúdos de nível introdutório e intermediário do App Inventor. $O$ canal acumula mais de 100 inscrições até o presente momento.

Palavras-chave: Ensino de programação. Adolescentes. Videoaulas. APP Inventor. 


\section{UMA ABORDAGEM LÚDICA PARA O ENSINO DE PROGRAMAÇÃO PARA ADOLESCENTES NO CONTEXTO DA PANDEMIA DE COVID-19}

\section{INTRODUÇÃO}

O Brasil e o mundo vivem uma situação alarmante referente ao número de pessoas sem um emprego formal. Estudos do IBGE (Instituto Brasileiro de Geografia e Estatística) mostram que a taxa média de desocupação em 2019 foi de 11,9\%, o que equivale a um total de 12,6 milhões de pessoas (NERY, 2020). Essa situação é ainda mais crítica entre os jovens, pois estudos apontam que a taxa de desemprego nessa faixa etária é superior ao dobro da média geral (SILVEIRA, 2018) (BRASIL ECONÔMICO, 2018) (LIMA, 2018). Além dessa grande falta de disponibilidade de postos de trabalho, entre o público jovem, existe o agravante de que esses indivíduos ainda não possuem experiência no mercado de trabalho, o que costuma ser usado como justificativa para que não consigam um emprego e gera um ciclo vicioso de desocupação. Por isso, jovens, em sua maioria, preocupam-se com o seu futuro profissional e se esforçam para atingir o sucesso, ao mesmo tempo em que precisam escolher uma profissão que lhes traga satisfação pessoal e financeira (SOBROSA, 2014).

Inúmeros são os fatores que influenciam a decisão de carreira a ser seguida por jovens, o que tende a causar incertezas que dificultam o processo de escolha. Isso se reflete no alto número de estudantes do $3^{\circ}$ ano do ensino médio que ainda não optaram por uma carreira específica. Muitas vezes, tal indefinição, estendida até a universidade, é apontada como causa de evasão de cursos superiores, o que adia ainda mais a inserção dessa parcela da população no mercado de trabalho. Quando estudantes não têm condições financeiras de arcar com escolhas incertas, que é ocaso de muitos alunos oriundos de escolas públicas, a situação tende a ser ainda mais grave (GUIA DO ESTUDANTE, 2017) (BALMANT, 2011) (PORTAL EDUCAÇÃO, 2019). Ainda, o uso de critérios frágeis, como indicação de parentes e amigos ou perspectiva salarial, também pode induzir a uma decisão equivocada, cenário que poderia ser diferente se os jovens pudessem ter qualquer contato com a área profissional pretendida antes da decisão (MAGGI, 2013).

Em todo o Brasil e, em especial, em Santa Catarina, uma alternativa promissora de carreira para jovens profissionais encontra-se no setor tecnológico. A capital do estado, Florianópolis, é o 4ํㅡㄹ maior polo tecnológico do Brasil. Segundo dados da Associação Catarinense de Tecnologia (ACATE), essa área tem uma participação no Produto Interno Bruto (PIB) do estado de 5,6\% (PACHECO, 2018). Com efeito, a área já ultrapassou quatro vezes a receita da área de turismo na capital e concentra o maior número de startups per capita do Brasil (JORNAL NACIONAL, 2019).

Dentro da área tecnológica, uma das habilidades mais requisitadas é a programação de computadores (ClO, 2019), o que se justifica pelo amplo crescimento observado nos últimos anos de desenvolvimento de aplicativos para dispositivos móveis ou ferramentas para internet, além do campo da análise de dados, frequentemente tido celeiro de "carreiras do futuro". Inclusive, mesmo para profissões sem conexão direta com as tecnologias de informação e comunicação (TIC), noções de programação tendem a ser proveitosas, como é o caso das cadeias produtivas no contexto da indústria 4.0, dada a utilidade da automação de processos. Assim, munidos desses conhecimentos, os jovens se tornam mais aptos a acompanhar as mudanças que estão por vir no mundo profissional. Ademais, a aprendizagem de programação de computadores traz contribuições importantes para 
aspectos gerais da vida dos estudantes, como o desenvolvimento de uma sistemática de resolução de problemas, trabalho cooperativo e senso crítico, habilidades que são úteis para qualquer área profissional almejada. Por fim, criatividade, raciocínio lógico e competências ligadas à matemática, física, escrita e inglês também são diretamente exercitados no estudo de programação (PACHECO, 2018).

A partir desse cenário, ressalta-se a importância de dar aos alunos de escolas públicas uma oportunidade de aprendizado dos fundamentos da programação de computadores para que não percam oportunidades de capacitação e inserção profissional na área tecnológica. De fato, há uma crescente defesa do ensino de programação para adolescentes por especialistas em educação de todo o mundo e, cada vez mais, disseminam-se, na literatura, diferentes métodos lúdicos com essa finalidade (PAYNE, 2015) (CELLAN-JONES, 2014) (LIVINGSTONE, 2013) (HARDESTY, 2015), o que inclui a sua utilização por pesquisadores brasileiros (GARLET, 2016), (SILVA, 2019). E esta tendência já é realidade no Brasil, ao menos na rede privada de ensino, que conta com um número cada vez maior de escolas destinadas ao ensino de programação para crianças e adolescentes.

Um projeto de extensão, formado por professores e estudantes da engenharia, foi iniciado em 2018 com o objetivo de desmistificar a área tecnológica e proporcionar a inclusão digital de alunos de escolas públicas da região, em parceria com a prefeitura municipal. O projeto atendeu alunos do $9^{\circ}$ ano e realizou atividades tais como palestras, oficinas de programação, rodas de conversa e visitação ao campus da instituição. Os resultados foram considerados positivos e incentivaram a equipe a dar continuidade ao projeto com vistas a atender um número maior de estudantes.

Entretanto, em março de 2020, quando começaram os preparativos para as atividades do projeto, as escolas em todo o país foram fechadas devido à pandemia do novo coronavírus. Com isso, adotaram-se aulas em regime não presencial (SOUZA, 2020). Segundo uma pesquisa do Instituto DataSenado, por causa da pandemia de Covid-19, entre os quase 56 milhões de alunos matriculados na educação básica e superior no Brasil, $35 \%$ tiveram as aulas suspensas e $58 \%$ passaram a ter aulas remotas (CHAGAS, 2020).

Com a crença na importância de seguir com a realização do projeto e sem a possibilidade de execução de atividades presenciais, foi decidido mudar a metodologia de ensino e aprendizagem para atividades não presenciais. Dessa forma, a equipe optou por gravar vídeos didáticos e disponibilizá-los em uma plataforma de acesso público na internet. Com o canal, além das escolas parceiras, foi possível difundir a programação em ampla escala e aumentar o público-alvo do projeto, o que fornece um serviço educativo à sociedade em geral. Além disso, os vídeos produzidos podem ser utilizados como material de apoio para futuras edições presenciais do projeto, o que permite aos participantes um acesso mais humanizado do que a tradicional consulta em apostilas. Com efeito, as tecnologias de informação e comunicação (TIC), no contexto das atividades não presenciais, permitem a democratização do acesso ao conhecimento acadêmico e profissional. Assim, tem-se a esperança de contribuir para diminuir as injustiças sociais, a pobreza, a desigualdade de gênero, assim como auxiliar o crescimento econômico.

Os Anais do COBENGE 2021 serão publicados incluindo a versão completa de todos os trabalhos aprovados e com a inscrição paga de pelo menos um dos autores no evento. É, portanto, extremamente importante que o preparo da versão digital de sua contribuição esteja de acordo com estas instruções.

Os Coordenadores de Área, designados pela Comissão Científica do COBENGE 2021, terão à sua disposição cópias eletrônicas de cada trabalho no sistema do evento, para a sua correspondente revisão por especialistas. 


\section{MATERIAIS E METODOLOGIA}

Inicialmente, o projeto estava previsto para ocorrer presencialmente, com oficinas realizadas nas escolas parceiras. Devido à pandemia do novo coronavírus e à suspensão das aulas presenciais nas escolas públicas parceiras deste projeto, o primeiro passo para a continuação desta atividade de extensão foi alterar a metodologia dos trabalhos. Assim, iniciou-se a procura por soluções não presenciais para que se mantivesse o objetivo de ensinar programação para adolescentes com uma abordagem prática e lúdica. Especificamente, o escopo do projeto foi modificado para a produção de videoaulas assíncronas, o que permitiria uma ampliação do número de estudantes a ser atendido. Dessa forma, o conteúdo ministrado fica disponível por tempo indeterminado, o que permite que o público possa revisar a apresentação quantas vezes quiser.

A fim de se ter sempre o público motivado e interessado na continuidade do projeto, optou-se por uma linguagem de desenvolvimento de software que fosse adequada a propósitos didáticos, além de ter uma capacidade de atrair a atenção dos jovens. A ferramenta escolhida foi o MIT App Inventor, que tem como objetivo a criação de aplicativos para dispositivos com sistema operacional Android (celulares, tablets), o que se justifica pelo fator motivacional e pela familiaridade da juventude atual com esses equipamentos eletrônicos. Assim, o App Inventor cumpre os critérios desejados em nível educacional, prático e lúdico. Com uma concepção intuitiva, essa linguagem de programação se baseia na montagem de blocos em esquema de quebra-cabeça, o que facilita a detecção de erros no código.

Nas edições anteriores da atividade de extensão, foi elaborada uma apostila que funcionava como roteiro para as aulas presenciais. Tal documento começa com uma introdução motivacional para a área de programação. Na sequência, traz um capítulo sobre Scratch, que é uma linguagem de programação desenvolvida pelo Massachusetts Institute of Technology (MIT) e que possui um forte apelo visual, o que a torna adequada para um público mais jovem, embora ela tenha maior simplicidade e limitações. Posteriormente, apresenta-se o micro:bit da BBC, que consiste em uma placa de circuitos para desenvolvimento de hardware de baixo custo.

Com a decisão por apresentar uma nova plataforma de desenvolvimento para o público-alvo, foi necessário atualizar a apostila do projeto, a qual serviria de texto-base para as videoaulas. Para facilitar a aprendizagem do assunto, foram utilizados diversos exemplos, com a explanação de todos os passos necessários para a implementação dos códigos.

Uma vez preparado o material de apoio, iniciou-se o processo de gravação e edição dos vídeos, cujo detalhamento será descrito na seção 3. Para tanto, houve uma etapa de aprendizagem das ferramentas de preparação de conteúdo de multimídia.

Após a gravação e a edição das videoaulas, criou-se um canal no YouTube, que é uma das maiores plataformas de vídeos da internet e iniciou-se um processo de divulgação do projeto. A fim de se ter uma personalização do projeto, a sua logo foi atualizada, a qual funciona como um símbolo para o canal. Também foi criada uma vinheta colorida e divertida.

No Youtube, as caixas de comentários são bastante utilizadas e podem possibilitar o esclarecimento de dúvidas, além da troca de informações entre pessoas com diferentes níveis de conhecimento sobre os temas abordados. A plataforma também traz diversas estatísticas sobre as visualizações, o que serve para avaliar o alcance do projeto e a sua aceitação por parte do público. 


\section{OS VÍDEOS}

Ao total, 8 roteiros de videoaulas foram elaborados pelos bolsistas do projeto, sendo avaliados e aprovados pela equipe de docentes. O primeiro deles tem o propósito de apresentar os integrantes do projeto, a área de programação e os conteúdos a serem ministrados nas outras videoaulas. Na parte de conteúdo propriamente dito, o $2^{\circ}$ vídeo mostra os detalhes para criação de um novo aplicativo no site no App Inventor. Em seguida, os vídeos 3 e 4 começam, respectivamente, com a explanação das duas interfaces da ferramenta, quais sejam, Designer (voltada para a construção dos elementos gráficos do aplicativo) e Blocos (responsável pela definição das funcionalidades e da lógica). O estudo de caso dos vídeos 3 e 4 compreende um programa que troca a cor de fundo e do texto em um quadrado na tela do celular quando o usuário seleciona um determinado botão. No $5^{\circ}$ vídeo, demonstra-se como transferir o aplicativo, desenvolvido no computador, para 0 celular do usuário. No $6^{\circ}$ e $7^{\circ}$ vídeo, faz-se uma aplicação dos conhecimentos precedentes para a criação de uma calculadora com operações aritméticas básicas. Por último, no $8^{\circ}$ vídeo, realiza-se uma calculadora de índice de massa corporal (IMC), que é uma aplicação com relevância prática para a saúde das pessoas. A subseção a seguir apresenta a descrição das videoaulas desenvolvidas.

\subsection{Vídeo 1: Introdução do canal}

O vídeo de introdução do canal tem o objetivo de apresentar a equipe executora, resumir o escopo do projeto e, principalmente, motivar o público para o conhecimento e interesse em programação e tecnologia em geral. Perspectivas de mercado de trabalho são também salientadas, com destaque para a necessidade de se formarem cada vez mais novos programadores no mundo. Com efeito, qualquer pessoa possui capacidade de aprender e de fazer parte dessa área.

Inicialmente, os dois bolsistas do projeto, alunos da Engenharia de Telecomunicações, apresentam-se e mencionam as ideias centrais do projeto. Em seguida, explicam a mudança na metodologia de ensino para o contexto de videoaulas educacionais, com a adaptação do conteúdo das oficinas presenciais realizadas em escolas públicas parceiras, como ocorreu em anos anteriores.

Durante o vídeo, os alunos enfatizam a importância da programação para a realização das atividades do dia a dia, cujas aplicações se relacionam com redes sociais, jogos, aulas remotas, casa inteligente, o que serve para melhorar a qualidade de vida das pessoas, facilitar a comunicação ou ser uma forma de lazer.

Depois disso, apresenta-se o App Inventor, que é a ferramenta didática escolhida para ministrar o conteúdo, a qual funciona online, é gratuita e voltada para a criação de aplicativos para celulares ou tablets. Assim, o estudante necessita apenas de um computador com acesso à internet para utilizá-la.

A dupla de bolsistas enfatiza que, a partir de uma abordagem prática e lúdica, com a construção de jogos e programas básicos, como, por exemplo, uma calculadora, é possível estimular a aprendizagem de lógica de programação, juntamente com a criação da interface gráfica dos aplicativos.

Dessa maneira, mostra-se que o público pode deixar de ser mero usuário de tecnologia para se tornar criador de seus próprios jogos e ferramentas, o que consiste em um convite para que se dê sequência ao curso nos demais vídeos do canal. 


\subsection{Vídeo 2: App Inventor - Como iniciar um projeto no App Inventor}

Com uma abordagem mais prática, o segundo vídeo ensina os primeiros passos para a criação de um aplicativo através da linguagem de programação App Inventor.

$\mathrm{Na}$ apresentação, exibe-se o link da plataforma a ser utilizada, o que é feito a partir de um navegador de internet. Informações importantes sobre a tela inicial da ferramenta são explicadas, com o intuito de ambientar o público-alvo. Destaca-se também a importância de ter um e-mail válido para o cadastro no site do App Inventor, o que corresponde ao login de acesso pessoal.

Após a entrada na plataforma, demonstra-se como realizar a alteração do idioma para o português. Com isso, pode-se dar início ao processo de criação de um novo projeto. Para facilitar o entendimento, ilustra-se essa etapa de ambientação com um passo a passo que começa com a inserção do nome do novo projeto e passa por demais configurações básicas.

Por fim, para dar um sentido de continuidade e aprofundamento dos assuntos, convida-se o público a assistir aos demais vídeos do canal, que explicam o funcionamento das interfaces de desenvolvimento do App Inventor, que é o próximo tema a ser lecionado.

\subsection{Vídeo 3: App Inventor - Interface Designer}

Na criação de um aplicativo no App Inventor, são utilizadas duas interfaces: Designer e Blocos. Na primeira delas, implementa-se a parte gráfica do programa, o que pode incluir a inserção de elementos como botões, cores, caixas de diálogo ou de seleção, legendas, entre outros. Na interface Blocos, define-se detalhadamente a funcionalidade de cada componente inserido na interface Designer. Assim, por exemplo, quando o usuário clica em um botão, o aplicativo executa a operação lógica que foi determinada na interface Blocos.

Desse modo, no terceiro vídeo do canal, apresenta-se a interface Designer do App Inventor. Essa interface é dividida em cinco campos: Paleta, Visualizador, Componentes, Mídia e Propriedades. São abordados os principais elementos de cada um dos cinco campos, com exemplos ilustrativos de sua utilidade prática.

Em especial, destaca-se o campo visualizador, que serve para simular a tela de um celular, o que permite que se tenha uma prévia da aparência do aplicativo a ser desenvolvido.

Em seguida, o vídeo mostra a inserção de componentes gráficos em um aplicativo através da adição de três botões nas cores azul, vermelho e amarelo. Esses componentes são inseridos e configurados por meio de propriedades como cor, tamanho, posição, fonte de texto e demais tópicos de formatação e organização. Brevemente, expõe-se um rol ilustrativo dos principais itens de configuração.

No final, mais uma vez, faz-se um convite para que o público dê prosseguimento ao curso nos demais vídeos do canal, especificamente, o vídeo da interface Blocos, que é responsável por dar funcionalidade aos componentes inseridos na interface Designer.

\subsection{Vídeo 4: App Inventor - Interface Blocos}

O vídeo sobre a interface Blocos é a sequência natural do assunto explorado no vídeo 3, que trata da interface Designer. Dessa vez, apresenta-se a lógica de programação dos componentes inseridos previamente, o que consiste na implementação interna do programa, ou seja, estabelece-se o conjunto de ações a serem executadas e a ordem em que devem ser realizadas.

A interface Blocos é dividida em três campos: blocos, mídia e visualizador. No vídeo, abordam-se os componentes mais relevantes de cada um dos campos, com a indicação de 
exemplos práticos. Destaca-se o campo visualizador, responsável por fornecer uma área de trabalho para a inclusão da lógica de programação que serve de base para os aplicativos.

Em seguida, o vídeo demonstra a inserção de blocos lógicos em um aplicativo, os quais são arrastados para o campo visualizador. Assim, explica-se, detalhadamente, como se define a ação a ser realizada por cada um dos botões inseridos no vídeo 3, o que permite que o aplicativo possa funcionar efetivamente.

Após a conclusão do desenvolvimento das partes gráfica e lógica, os espectadores são convidados a baixar o aplicativo em seu smartphone e testá-lo. No vídeo 4, testa-se o programa através de um simulador de celular. Desse modo, quando o usuário toca em um botão (azul, vermelho ou amarelo), as cores de fundo e do texto são alteradas para a cor selecionada, o que é o comportamento esperado do programa, conforme se verifica na Figura 1.

Novamente, no encerramento da aula, pede-se que todo o público prossiga seus estudos nos demais vídeos do canal.

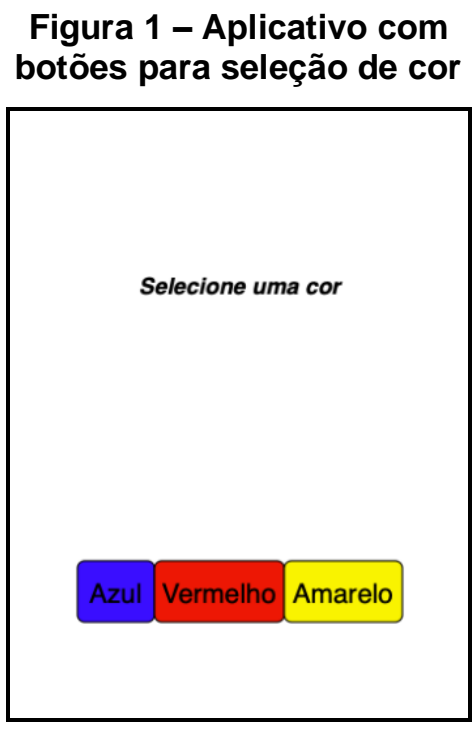

Fonte: autor

\subsection{Vídeo 5: App Inventor - Como carregar o aplicativo para o celular}

O vídeo 5 tem como objetivo ensinar, de forma simples e didática, a transferir o aplicativo desenvolvido de um computador para o celular.

Uma parcela do processo deve ser realizada diretamente no celular e a outra parte precisa ser feita em um computador com acesso ao projeto que se deseja testar. Para exemplificar o processo, utiliza-se o código criado no vídeo 6 . Primeiramente, ensina-se a baixar o aplicativo do App Inventor no celular, chamado de MIT AI2 Companion. Depois disso, mostra-se um passo a passo de como passar o aplicativo desenvolvido para o celular. Ao final do processo, testa-se o programa no telefone móvel e constata-se que a sua operação se encontra de acordo com o esperado.

\subsection{Vídeo 6: App Inventor - Como fazer aplicativo de calculadora - Parte 1}

Os vídeos 6 e 7 aplicam os conceitos vistos nas apresentações anteriores para a criação de um aplicativo de calculadora básica. Salienta-se que, mesmo aqueles que não 
tenham conhecimento na área de programação, podem acompanhar e desenvolver este projeto. A escolha desse programa é motivada pela sua simplicidade e, ao mesmo tempo, utilidade prática. No vídeo 6, especificamente, desenvolve-se um aplicativo de soma de 2 algarismos.

Os procedimentos para o acesso à plataforma do App Inventor, login e criação de um novo projeto são relembrados, como um reforço de aprendizado. Em seguida, destacam-se as interfaces (Designer e Blocos) utilizadas no desenvolvimento do aplicativo.

Inicia-se a criação do aplicativo na interface Designer, com a descrição de todos os componentes e configurações básicas, além de um passo a passo para a inserção de cada elemento da calculadora.

Em seguida, define-se a lógica de programação através da interface Blocos. Inserem-se os componentes necessários para dar funcionalidade à calculadora. Ao final, realiza-se um teste do aplicativo, o que requer conhecimentos do vídeo 5.

Um convite para dar continuidade na aprendizagem de programação encerra o vídeo.

\subsection{Vídeo 7: App Inventor - Como fazer aplicativo de calculadora - Parte 2}

O vídeo 7 dá sequência ao projeto da calculadora e faz a adição das demais operações aritméticas fundamentais (subtração, divisão e multiplicação).

Mais uma vez, inicia-se o desenvolvimento na interface Designer com a inserção de novos botões, os quais se referem às novas operações matemáticas. Cores, posição e demais configurações gráficas são explicadas em detalhes. Em seguida, através da interface Blocos, implementa-se a parte lógica do programa, responsável pela funcionalidade de cada componente adicionado. A Figura 2 ilustra a tela inicial do aplicativo da calculadora, em que os botões possuem maior destaque.

Por fim, realizam-se testes para validar o funcionamento do aplicativo. Números são escolhidos aleatoriamente para não invalidar a verificação do aplicativo e as 4 operações são feitas com sucesso.

Um novo convite para dar sequência na aprendizagem de programação encerra o vídeo.

Figura 2 - Aplicativo calculadora desenvolvido no App Inventor.

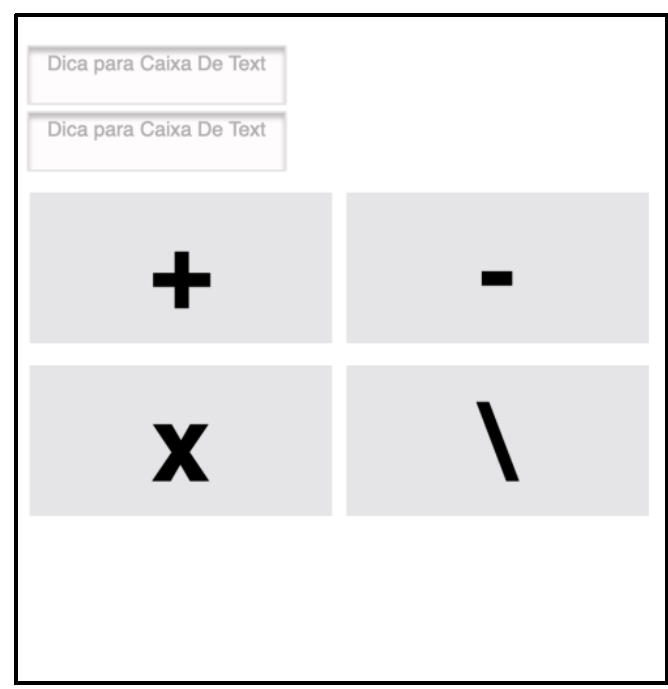

Fonte: autor 


\subsection{Vídeo 8: App Inventor - Calculadora IMC}

O vídeo 8 do canal ensina como desenvolver uma calculadora de índice de massa corporal (IMC), que é uma métrica internacional de cálculo de obesidade utilizada pela Organização Mundial de Saúde (OMS). Especificamente, calcula-se essa medida pela fórmula IMC = peso/(altura*altura) e compara-se o resultado obtido com os valores da tabela de IMC adotada pela OMS (OMS, 1995). Mais uma vez, a motivação para a escolha desse programa decorre de sua simplicidade e utilidade prática.

No início do vídeo, com o propósito de reforçar a aprendizagem de conceitos de videoaulas anteriores, o bolsista recapitula o passo a passo para a criação de um novo projeto. Posteriormente, ensina a inserir, na interface Designer, todos os blocos necessários para o funcionamento da calculadora. Demonstra-se também como se realizam as configurações funcionais e estéticas para esses componentes.

Após concluir o trabalho relativo à aparência do programa, demonstra-se, na interface Blocos, todo o desenvolvimento da lógica que será responsável pela funcionalidade de cada componente adicionado e pelo programa em geral.

Para validar o código criado para a calculadora IMC, conforme ilustra a Figura 3, testa-se o aplicativo com diferentes entradas de altura e peso. Incentiva-se que os estudantes façam essa verificação com o seu próprio peso e altura, além dos dados de pessoas de suas famílias.

Figura 3 - Calculadora IMC desenvolvida no APP Inventor

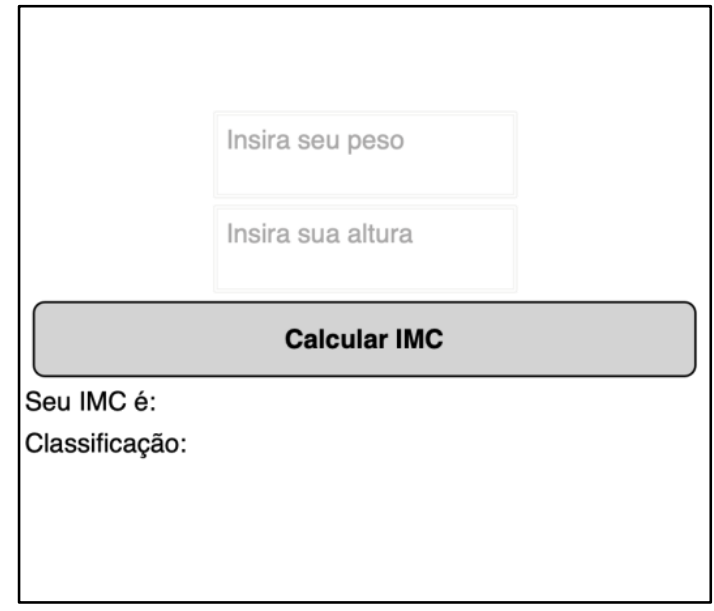

Fonte: autor

\section{$4 \quad$ RESULTADOS}

Em termos qualitativos, apesar de a equipe ter se deparado com uma mudança inesperada na metodologia de aplicação das oficinas do projeto, migrar o conteúdo do material desenvolvido para um veículo digital foi positivo para os objetivos almejados. De fato, essa alteração proporcionou uma expansão do alcance do público beneficiado, pois, com o material disponibilizado na Internet, não apenas estudantes de escolas públicas do município da instituição de ensino da equipe executora têm a oportunidade de aprender uma nova linguagem de programação, mas também qualquer pessoa com um computador que tenha uma conexão com a Internet. Além disso, o conteúdo disponível na internet 
poderá servir de material de apoio para o projeto numa eventual retomada do modelo de atividades presenciais.

Em aspectos quantitativos, ao todo, foram desenvolvidos quatro aplicativos de caráter lúdico e didático com base na ferramenta App Inventor. Por enquanto, constam 8 vídeos inseridos no canal do projeto no YouTube, o que corresponde a um total de quase duas horas de conteúdo. Neste momento, o canal tem mais de cem inscritos e a quantidade de visualizações obtidas em cada vídeo e no canal como um todo varia constantemente. Agora, o público-alvo se estende em escala mundial, pois a plataforma distribui os vídeos em toda a Internet.

Em virtude dos resultados positivos observados, submeteu-se o projeto novamente a um edital de extensão da instituição de ensino da equipe, sendo contemplado para dar sequência no ano de 2021. Um dos objetivos é continuar a produzir vídeos para expandir o canal no YouTube e, também, deseja-se a realização de encontros síncronos com os alunos das escolas públicas parceiras para aumentar o contato com o público, a fim de difundir o saber tecnológico e oportunizar novos horizontes aos jovens.

\subsection{Problemas enfrentados e soluções propostas}

Este projeto apresentava um forte caráter presencial e interativo com os participantes das oficinas de programação nas escolas públicas parceiras. A equipe discente iniciou o projeto antes do isolamento e era composta por 5 alunos, sendo 2 bolsistas remunerados e 3 voluntários. Com a pandemia, os desafios iniciaram com a necessidade de adaptação da equipe a uma rotina de trabalho remoto, o que passava pelas dificuldades de separação de tempo entre afazeres domésticos e os trabalhos do projeto. $O$ ensino de programação requer considerável nível de criatividade e inovação, o que necessita de maior interação entre as pessoas e esse foi um obstáculo relevante. As reuniões semanais passaram a ser realizadas através de videoconferências. Com o decorrer do ano, devido à pandemia, os alunos voluntários optaram por sair do projeto, permanecendo apenas os 2 bolsistas, o que resultou no acréscimo da carga individual de trabalho para os membros remanescentes.

Em decorrência do novo cenário, também houve a necessidade de modificar e reavaliar a metodologia de apresentação do conteúdo, a fim de atrair a atenção do público de forma remota. Além disso, foi fundamental aprender a gravar e editar vídeos de caráter didático e lúdico, o que, inicialmente, foi desafiador, mas resultou no aumento dos conhecimentos e habilidades da equipe executora, em especial dos bolsistas do projeto. Deve-se enfatizar que a equipe não tinha experiência pregressa na criação de videoaulas.

\section{CONSIDERAÇÕES FINAIS}

A realização do projeto no contexto da pandemia do novo coronavírus trouxe novo aprendizado e novas perspectivas à equipe executora. Aos bolsistas proporcionou desenvolver habilidades na área docente, no desenvolvimento e na criação de material didático e audiovisual. Vale a pena ressaltar que a dupla de bolsistas não tinha conhecimento prévio sobre o App Inventor, o que serviu para incrementar o seu arcabouço técnico na área de programação. Além disso, do ponto de vista social, destaca-se que difundir o conhecimento, em meio a uma calamidade mundial, trouxe esperança aos mentores e colaboradores deste projeto. Isso também serviu para um aumento das perspectivas de capacitação profissional do público-alvo do projeto, uma vez que se permitiu um primeiro contato com o universo da programação de computadores, que é uma área estratégica na sociedade. 


\section{REFERÊNCIAS}

BALMANT, Ocimara. Metade dos alunos do 30 ano não sabe qual carreira seguir. O Estado de São Paulo. 22 de ago. 2011. Disponível em:

https://www.estadao.com.br/noticias/geral,metade-dos-alunos-do-3-ano-nao-sabe-qualcarreira-seguir-imp-,761850. Acesso em 07 mai. 2021.

BRASIL ECONÔMICO. Desemprego no Brasil afeta mais os grupos de jovens, mulheres e negros. 17 out. 2018. Disponível em:

https://economia.ig.com.br/2018-08-17/desemprego-mulher-jovem-negra.html. Acesso em 7 mai. 2021.

CELLAN-JONES, Rory. A computing revolution in schools. BBC, 1 set. 2014. Disponível em: https://www.bbc.com/news/technology-29010511. Acesso em 07 mai. 2021.

CHAGAS, Elisa. DataSenado: quase 20 milhões de alunos deixaram de ter aulas durante pandemia. Agência Senado, 12 ago. 2020. Disponível em:

https://www12.senado.leg.br/noticias/materias/2020/08/12/datasenado-quase-20-milhoesde-alunos-deixaram-de-ter-aulas-durante-pandemia. Acesso em 07 mai. 2021.

CIO. CIO from IDG, 06 dez. 2019. As habilidades técnicas mais desejadas na TI para 2020. Disponível em:

https://cio.com.br/carreira/as-habilidades-tecnicas-mais-desejadas-na-ti-para-2020/.

Acesso em 07 mai. 2021.

GARLET, D et al. Uma Proposta para o Ensino de Programação de Computadores na Educação Básica. TCC, Universidade Federal de Santa Maria, Rio Grande do Sul, 2016. Disponível em:

https://repositorio.ufsm.br/bitstream/handle/1/12961/TCCG SIFW 2016 GARLET DANIE LA.pdf? sequence=1\&isAllowed=y. Acesso em 07 mai. 2021.

GUIA DO ESTUDANTE. Mais da metade dos estudantes ainda não decidiram qual faculdade fazer. Abril, 16 mai. 2017. Disponível em:

https://guiadoestudante.abril.com.br/universidades/mais-da-metade-dos-estudantes-aindanao-decidiram-qual-faculdade-fazer/. Acesso em 07 mai. 2021.

HARDESTY, Larry. Teaching programming to preschoolers. Mit News Office. 11 mar. 2015. Disponível em: http://news.mit.edu/2015/teaching-preschoolers-programming-0312. Acesso em 07 mai. 2021.

JORNAL NACIONAL. G1, 22 jun. 2019. Indústria da tecnologia já supera a do turismo em Florianópolis. Disponível em:

https://g1.globo.com/jornal-nacional/noticia/2019/06/22/industria-da-tecnologia-ja-superaa-do-turismo-em-florianopolis.ghtml. Acesso em 07 mai. 2021.

LIMA, Nataniel. Jovens brasileiros sofrem com a falta de oportunidades e baixa confiança em sua geração. Oitomeia. 23 jan. 2018. Disponível em:

https://www.oitomeia.com.br/noticias/2018/01/23/jovens-sofrem-com-falta-deoportunidades-e-baixa-confianca-em-sua-geracao-no-brasil/. Acesso em 07 mai. 2021. 
LIVINGSTONE, lan; HOPE, Alex. Next Gen, Nesta, 22 out. 2013. Disponível em: https://www.nesta.org.uk/report/next-gen/. Acesso em 07 mai. 2021.

MAGGI, Lecticia. Metade dos jovens escolhe carreira sem conhecer profissão. Veja, 23 mai. 2013. Disponível em:

https://veja.abril.com.br/educacao/metade-dos-jovens-escolhe-carreira-sem-conhecerprofissao/. Acesso em 07 mai. 2021.

NERY, Carmen. Agência de Noticias IBGE, 31 jan. 2020. Desemprego cai para 11,9\% na média de 2019; informalidade é a maior em 4 anos. Disponível em: https://agenciadenoticias.ibge.gov.br/agencia-noticias/2012-agencia-denoticias/noticias/26741-desemprego-cai-para-11-9-na-media-de-2019-informalidade-e-amaior-em-4-anos. Acesso em 07 mai. 2021.

ORGANIZAÇÃO MUNDIAL DE SAÚDE. Physical status: The Use and Interpretation of Anthropometry. WHO Technical Report Series n.854. Geneva, 1995.

PACHECO, Juliano A.; NETO, Miguel R. ACATE Observatory: 2018 Santa Catarina Technology Industry Overview. ACATE. Florianópolis, SC, 2018.

PAYNE, Bryson. Ensine seus filhos a programar. 1a Ed. São Paulo: Novatec, 2015.

PORTAL EDUCAÇÃO. Mais de 60\% dos jovens não sabem qual carreira seguir. Disponível em:

https://siteantigo.portaleducacao.com.br/conteudo/artigos/iniciacao-profissional/mais-de60-dos-jovens-nao-sabem-qual-carreira-seguir/68565. Acesso em 07 mai. 2021.

SILVA, Diego et al. Introdução à programação: uma abordagem lúdica para adolescentes. In: XLVII Congresso Brasileiro de Educação em Engenharia, 2019, Fortaleza. Anais. Fortaleza. Disponível em:

http://www.abenge.org.br/sis submetidos.php?acao=abrir\&evento=COBENGE19\&codigo =COBENGE19 00121 00002508.pdf. Acesso em 07 mai. 2021.

SILVEIRA, Daniel. Desemprego entre os jovens é superior ao dobro da taxa geral, aponta IBGE. G1 Rio, 17 out. 2018. Disponível em:

https://g1 .globo.com/economia/noticia/2018/08/17/desemprego-entre-os-jovens-esuperior-ao-dobro-da-taxa-geral-aponta-ibge.ghtml. Acesso em 07 mai. 2021.

SOBROSA, Gênesis M. R. et al. Perspectivas de futuro profissional para jovens provenientes de classes socioeconômicas desfavorecidas. Temas psicol., Ribeirão Preto, v. 22, n. 1, p. 223-234, abr. 2014. Disponível em: http://dx.doi.org/10.9788/TP2014.1-17. Acesso em 07 mai. 2021.

SOUZA, Vitor; MAGNONI Jr., Lourenço. O que as estatísticas retratam sobre a educação básica em tempos de covid-19. Revista Epistemologia e Práxis Educativa, Teresina, ano 03, n. 03, v. 03 set./dez., 2020. ISSN - 2674-757X. 


\title{
A LUDIC APPROACH FOR TEACHING PROGRAMMING TO TEENAGERS IN THE COVID-19 PANDEMIC CONTEXT
}

\begin{abstract}
The area of information and communication technologies (ICT) has contributed significantly to the economic development of many Brazilian cities in recent years, which represents a great opportunity for professional insertion of young people. This paper reports the results of an extension project that has been taking place since 2018, which proposes to present the technological area as a viable job market for students of the 9th year of public schools through computer programming languages workshops. In the first editions of the project, teen students were introduced to the world of technology through the teaching of programming, which was based on playful approaches that made use of didactic tools such as Scratch, Lightbot, and micro:bit. In 2020, due to the social distance rules imposed by the new coronavirus pandemic, the project's scope was modified. The working team adapted the support material and produced video lessons to teach programming through the creation of mobile applications using the educational tool App Inventor, which was chosen due to motivational purposes. Such videos were made available on a YouTube channel. In total, eight videos were recorded by fellowship students of the project, which encompass introductory and intermediate level content of App Inventor. The channel has more than 100 subscriptions to date.
\end{abstract}

Keywords: Programming teaching. Teen students. Video lessons. App Inventor. 